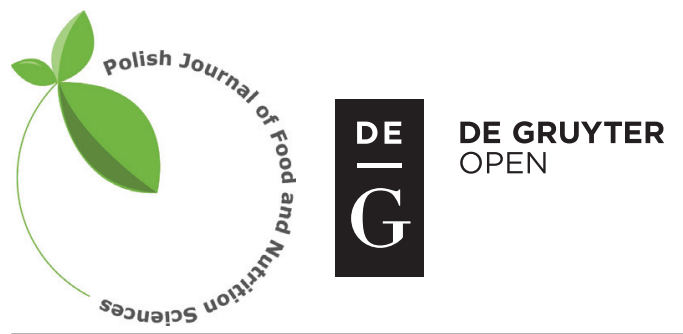

Pol. J. Food Nutr. Sci., 2017, Vol. 67, No. 4, pp. 283-292

DOI: $10.1515 /$ pjfns-2016-0031 http://journal.pan.olsztyn.pl

Original research article

Section: Food Quality and Functionality

\title{
Determinants of the Sensory Quality of Pótgessek in Relation to Volatile Compounds and Chemical Composition
}

\author{
Katarzyna Nowicka*, Danuta Jaworska, Wiestaw Przybylski, Ewa Górska, Krzysztof Tambor, Andrzej Póttorak
}

\author{
Department of Food Gastronomy and Food Hygiene, Faculty of Human Nutrition and Consumer Sciences, \\ Warsaw University of Life Sciences, Nowoursynowska 159 C, 02-776 Warsaw, Poland
}

Key words: goose meat, volatile profile, flavor, sensory quality

The objective of this study was to determine the sensory quality of a specific Polish traditional product made from cured and then smoked goose meat (pótgęsek) in relation to its volatile compounds and chemical composition. In general, the examined samples contained $66.2 \%$ water, $12.2 \%$ fat, $17.9 \%$ protein, $1.8 \%$ connective tissue, and $2.3 \% \mathrm{NaCl}$. Moreover, 47 volatile compounds were identified and quantified. The typical decomposition products derived from lipid oxidation, amino acid degradation, carbohydrate fermentation and microbial esterification were the main volatiles detected in all the samples. The volatiles generated by the smoking process and the ones originating from spices were also observed. The results of the sensory evaluation indicated that all the samples of the analyzed products were characterized by a high overall quality. Results of the Principal Component Analysis (PCA) showed, however, that specific groups of products have their own unique sensory profile. Additionally, the sensory analysis confirmed the significant role of the chemical composition and volatile compounds in the development of the overall quality of pótgessek.

\section{INTRODUCTION}

In recent years consumers, producers and regional authorities have shown a growing interest in high quality food produced with traditional methods. After the period of fascination for convenience and fast food, more and more consumers started to buy traditional products as they associate them with unique taste, aroma and appearance, generally linking these features with high quality. Because of factors such as industrialization of food production, introduction of European food safety regulations and development of innovative products, the characterization of the typical sensory traits of the traditional products becomes essential [Cayot, 2007]. For some consumers traditional food is mostly linked to sensory properties, while for others the most frequent association is homemade [Guerrero et al., 2010]. According to literature, Polish consumers are less inclined, than other Europeans, to accept innovation in traditional food products. It is true especially in relation to the intrinsic product attributes and in particular to the sensory quality. It is generally acknowledged that the expression 'traditional food' refers to products made from specific raw materials, and specific recipe known for a long time, and/or with a specific process [Z̈akowska- Biemans et al., 2016]. Nowadays such food is very popular in Poland; 1572 products are registered in the national List of Traditional Products, among which meat products represent the share

\footnotetext{
* Corresponding Author: Tel.: + 48793575 585;

E-mail: katarzyna_nowicka@sggw.pl (K. Nowicka)
}

of approximately $23 \%$. The sensory quality of meat products is created mainly by flavor and odor compounds. Volatile compounds in raw meat products made from smoked raw meat originate mainly from the components of smoke, but also from lipolytic transformations, proteolysis, and transformations of hydrocarbons. Moreover, the aroma of the final product can also be created by various spices added during the production process [Marušić et al., 2011; Muriel et al., 2004]

One of the specific traditional products, registered in the above-mentioned national List of Traditional Products, is pótgęsek made from goose meat. Pótgęsek was known as a delicacy consumed willingly in one of the Polish region called Pomerania. Throughout the summer, young geese were fattened on pasture grass and in autumn only on carrots and oats. The geese were slaughtered in the late autumn, and pótgęsek produced from this meat was consumed from Christmas until the end of the carnival [Kluk, 1813]. Until today, pótgessek is produced from goose breast fillet with skin and cured in salt and spices for about 2 weeks. Finally goose breasts are smoked for about $2-4$ days at a low temperature. Alder, cherry or juniper wood is used for that process. Polish, German, English and French consumers appreciate the exceptional quality of pótgęsek. Due to the fact that there are few studies characterizing the quality and nutritional value of this traditional product, the aim of this study was to determine the sensory quality of goose meat products in relation to their volatile compounds and chemical composition. 


\section{MATERIALS AND METHODS}

\section{Samples}

The study was carried out on 21 samples of pótgessek made from meat of White Koluda goose. The products were obtained from three different producers (21 samples from 3 producers in 2 batches). The goose breast fillet with skin was used in the study. The samples were seasoned with the mixture of salt, nitrates and spices (400 g per kg) and kept at $4{ }^{\circ} \mathrm{C}$ and relative humidity of $75-80 \%$ for $1-2$ weeks. Afterwards, cold meat was washed with cold water to remove the excessive salt, then dried, and formed in rolls. All the dry-cured samples obtained from the meat of White Koluda goose underwent a cold smoking process $\left(16-22^{\circ} \mathrm{C}\right)$ for $2-7$ days. Once the smoking process was finished, cold meat was vacuum packed in order to avoid an excessive dehydration of the product before the evaluation.

The sensory analysis was conducted immediately after opening the packages. For the analysis of volatile compounds' profile, the remaining pieces of cold meat were cut in cubes of 20-30 g, packed in closed Ziploc bags and frozen at $-80^{\circ} \mathrm{C}$. Cold meat was stored for up to one month.

\section{Sensory analysis}

The sensory Quantitative Descriptive Analysis (QDA), with an unstructured, linear graphical scale; a $100 \mathrm{~mm}$ converted to numerical values (0-10 conventional units [c.u.]), was used for the sensory assessment [ISO 13299.2:2016]. The sensory quality was characterized on the basis of 20 sensory traits: 6 odor attributes (smoked meat aroma, fatty aroma, spicy aroma, sour aroma, sweet aroma, other aroma), 3 appearance attributes (homogeneity of meat tissue color, fat thickness, color of fat cover), 3 texture attributes (juiciness, tenderness, fibrosity), 7 attributes of flavor (smoked meat flavor, fatty flavor, spicy flavor, sour flavor, sweet flavor, salty taste, other flavor), and the overall quality.

The preparation of the samples for the sensory evaluation consisted of taking the pótgesek out of packages right before the analysis, and slicing cold meat in equal pieces, each $0.5 \mathrm{~cm}$ thick. Single slices were put into odorless, plastic, disposable containers closed with lids. The evaluation was carried out by a panel trained in the scope of the applied evaluation, the panel members have a long-term experience in conducting sensory evaluations according to the ISO 8586-2:1996 standard. Individual results were collected after each evaluation.

\section{PHYSICOCHEMICAL PARAMETERS}

\section{Acidity}

$\mathrm{pH}$ measurements of meat samples were performed using a 330i type WTW pH meter (Weiheim, Germany) and were conducted in triplicate.

\section{Chemical composition}

The content of water, protein, fat and ash was measured using the near-infrared spectrophotometer NIRFlex N-500 (Büchi, Flawil, Switzerland). The measurement was performed using NIRFlex Solids module of the spectral range of $12,500-400 \mathrm{~cm}^{-1}(780 \mathrm{~nm}<\lambda<2500 \mathrm{~nm})$ in reflectance mode. Portions of meat (50-100 g) were homogenized, and then placed in a glass Petri dish, with portion of meat $0.5 \mathrm{~cm}$ thick. The measurements were performed in triplicate using the 16-fold scan of the samples.

\section{Analysis of volatile compounds}

Extraction and analysis of volatile compounds from sample headspace were performed with the use of solid phase microextraction (SPME) and gas chromatography coupled with mass spectrometry (GCMS). Polydimethylsiloxane/divinylbenzene, $65 \mu \mathrm{m}$ (PDMS/DVB) absorption fiber was used (Supelco, USA) to extract volatile compounds from the headspace. Before each analysis SPME fiber was conditioned in a gas chromatograph injector (GC) at the temperature of $250^{\circ} \mathrm{C}$.

Samples of homogenized meat $(5 \mathrm{~g}$ ) were placed in a $20-\mathrm{mL}$ vial, closed with a cap with silicone-teflon sealing, and next heated to $37^{\circ} \mathrm{C}$ for $1 \mathrm{~h}$ in order to stabilize the concentrations of volatile compounds in the vial. After this step, SPME fiber was introduced to sample headspace for $45 \mathrm{~min}$. Next, the fiber was quickly transferred from the vial to the $\mathrm{GC}$ injector working in "splitless" mode and set to $250^{\circ} \mathrm{C}$, in order to desorb the extracted volatiles to the GC system.

Chromatographic separation was performed with the use of GC Agilent 6890, coupled with quadruple MS Agilent 5795 (USA). DB-5MS column (30 m, $0.25 \mathrm{~mm}, 0.25 \mu \mathrm{m}$, and 5\%-diphenyl-95\%-polydimethylsiloxane) was used with helium as carrier gas at the flow rate of $0.9 \mathrm{~mL} / \mathrm{min}$ (Agilent, USA). The GC oven was programmed as follows: initial temperature of $38^{\circ} \mathrm{C}$ was maintained for $10 \mathrm{~min}$, then increased to $200^{\circ} \mathrm{C}$ at the rate of $4^{\circ} \mathrm{C} / \mathrm{min}$ and maintained for $2 \mathrm{~min}$, then increased to $250^{\circ} \mathrm{C}$ at the rate of $20^{\circ} \mathrm{C} / \mathrm{min}$, and the final temperature was maintained for $7 \mathrm{~min}$.

Mass spectra were obtained in an Electron Ionization (EI) mode at $70 \mathrm{eV}$ in a scanning range of $20-350 \mathrm{~m} / \mathrm{z}$ (a.m.u). Temperatures of ion source and mass analyzer were set to $230^{\circ} \mathrm{C}$ and $150^{\circ} \mathrm{C}$, respectively. Data acquisition and analysis were carried out using a built-in data-handling program (Enhanced ChemStation) provided by the manufacturer of the GC/MS. Quantities of volatile compounds were reported as a relative percentage of the total peak area. The identification of the constituents was based on the comparison of their MS spectra with mass spectra libraries of Wiley $8^{\text {th }} \mathrm{Ed}$. and Nist 08 (US National Institute of Standards and Technology). Mass spectra targets were confirmed by comparing linear retention indices (LRI) calculated relatively to C6C20 alkanes with LRI database built in the NIST 08 mass spectra library. Calculation of LRI was made by the use of Amdis software (Automated Mass Spectral Deconvolution and Identification System, NIST, USA).

\section{Instrumental color measurement in $\mathbf{L}^{*} \mathbf{a} * \mathbf{b} *$ system}

Instrumental color analysis of pótgęsek samples was performed using a Minolta CR-400 chromo meter calibrated against a white plate $\left(L^{*}=98.45, a^{*}=-0.10, b^{*}=-0.13\right)$, using an $8 \mathrm{~mm}$ aperture, Illuminate D65 (6500 K color temperature) at a standard observation angle of $2^{\circ}$. Values for $\mathrm{L}^{*}$ (lightness ranging from 0 to $100 \%$ ), a* (color axis ranging from green- 
ness $\left(-a^{*}\right)$ to redness $\left.\left(+a^{*}\right)\right)$ and $b^{*}$ (color axis ranging from blueness $\left(-b^{*}\right)$ to yellowness $\left.\left(+b^{*}\right)\right)$ were measured. Measurements of the samples were conducted immediately after opening the packages and cutting cold meat into slices (from five locations including every quarter and the center surfaces of the slices).

\section{Statistical analysis}

The results were elaborated with the use of STATISTICA statistics package, version 12 (StatSoft, Inc. 2014) and Microsoft Excel 2007. Simple Pearson correlation coefficients between the examined traits were calculated. The results for the sensory evaluation were elaborated with the use of the Principal Component Analysis method (PCA). Based on the results of this analysis, 3 groups of samples varying in sensory quality were identified. These results were developed using one-way analysis of variance ANOVA. The significance of differences between means were calculated based on the least significant differences test (LSD).

\section{RESULTS AND DISCUSSION}

\section{Sensory evaluation}

The obtained results indicated that all the samples of the analyzed products were characterized by a high overall quality. The examined product was characterized by the greatest variation as for the following sensory attributes: intensity of spiciness, color homogeneity and fat cover, fat thickness, juiciness, fibrosity, intensity of salty taste, other and fatty flavors (Figure 1). These results show that the variability in the sensory quality of this traditional product is related to the fat content and quality, but it could also be caused by the added spices. This situation can result from decisions made by small producers to use various materials and technologies. The correlation analysis showed that the overall quality was positively correlated with the intensity of the smoked meat aroma and tenderness. The negative impact on the overall quality was confirmed for the following attributes: intensity of fatty aroma, fat thickness, intensity of fatty flavor, and fibrosity. These results showed that the panelists preferred meat products with a low fat content. The other significant, high $(\mathrm{r}=0.7 ; \mathrm{P} \alpha \leq 0.05)$ and positive correlations were obtained between spicy flavor and aroma, fatty flavor and fibrosity, whereas negative ones between fibrosity and tenderness, juiciness and other flavor, as well as sweet and salty taste.

Due to the high variability in several sensory descriptors, the principal component analysis (PCA) was performed. This method allows the analysis of variability in multiple surfaces based on the relationship among all analyzed traits and is frequently used in sensory studies. The results show that $45.48 \%$ of the total variability could be explained by two principal components (Figure 2). Component 1 was strongly associated in a negative way with the homogeneity of meat tissue color, tenderness and overall quality, and positively with fat thickness, fibrosity, fat flavor, fatty odor, and juiciness. Component 2 was positively associated with the aroma and flavor of smoked meat, and negatively with sweet odor as well as sour aroma and flavor. Figure 3 shows the distribution of all analyzed samples in the area created by two principal components. The samples were grouped into three clusters (Figure 3). The analysis of variance showed that they differed significantly in terms of smoked, fatty and sour odors. In flavor descriptors, significant differences were noted for smoked, fat, sour, and other notes. The differences between groups were noted also for color homogeneity, fat thickness, color, juiciness, tenderness, fibrosity, and overall quality (Figure 4). Mean values for each group demonstrated that each of them had its own unique sensory profile. The first group was characterized by the highest tenderness, overall quality and homogeneity of color and the lowest intensity of fatty flavor, fibrosity and juiciness (Figure 4). These results, the high overall quality assessment in particular, suggest that Polish consumers prefer low-fat meat, i.e. with low marbling and low intensity of fatty odor, and are unwilling to buy meat containing intramuscular fat, as they associate it with a higher caloric value and cholesterol content [Z̈akowska-Biemas et al., 2016].

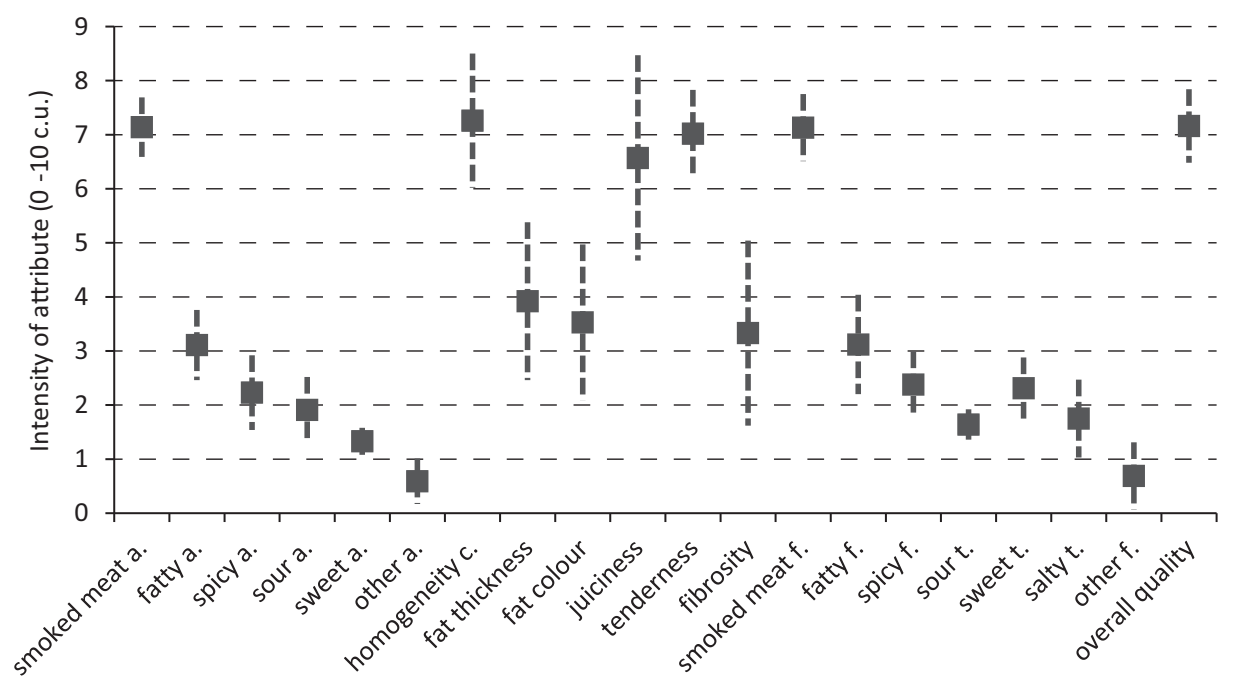

FIGURE 1. Characteristics of the sensory quality of pótgęsek presented as mean value with standard deviation; a. - aroma, f. - flavor, t.- taste. 


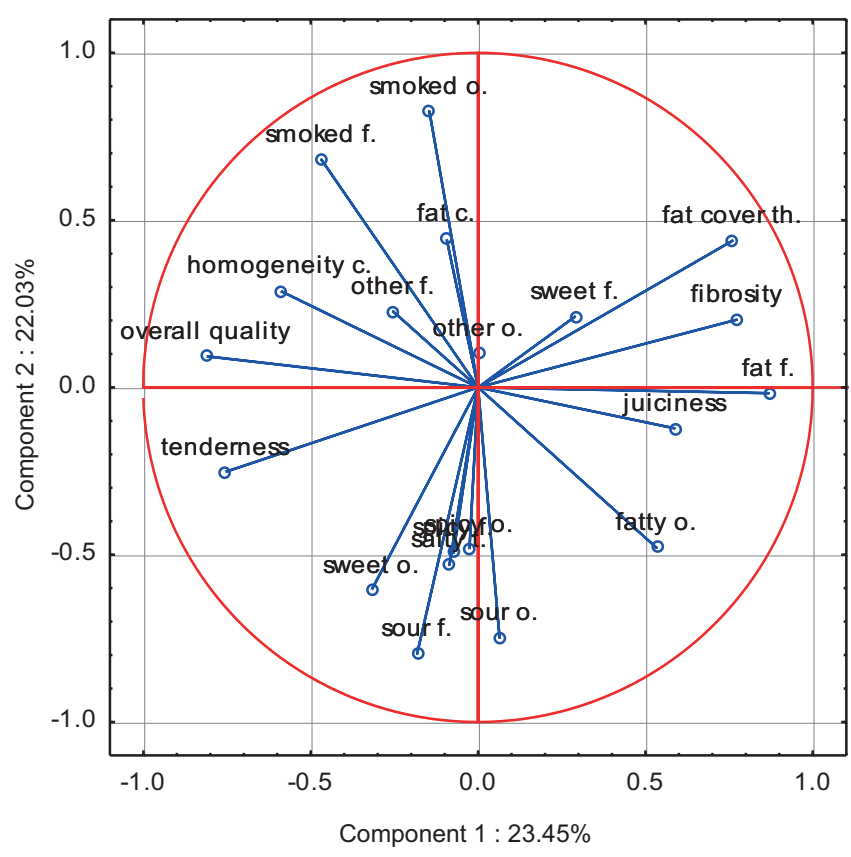

FIGURE 2. Results of the Principal Component Analysis (PCA) - spatial distribution of the sensory variable for two principal components. Explanations: $\mathrm{c}$ - color, $\mathrm{o}$ - odor, th - thickness, $\mathrm{f}$ - flavor, $\mathrm{t}$ - taste.

Moreover, a low content of intramuscular fat (IMF) and low perception of juiciness of meat confirmed the significant correlation between two distinguishing features - a lower content of intramuscular fat containing less unsaturated fatty acids reduces the perception of meat juiciness.

Group II was characterized by the lowest tenderness and homogeneity of meat tissue color. It was the most fibrous and juicy one with the highest intensity of fatty flavor and the highest fat thickness. Groups II and III were characterized by a similar sensory quality (Figure 4). These results confirmed clearly the correlation between fat content and juiciness of the meat [Dinh et al., 2006]. Group III was distinguished only by the highest intensity of sour odor.

\section{Chemical composition in relation to sensory quality}

The above-mentioned differences between the groups were reflected in the chemical composition of the analyzed products. The groups differed significantly as for their water, fat, protein and $\mathrm{NaCl}$ content as well as in $\mathrm{L}^{*}$ and $\mathrm{b}^{*}$ color parameters (Table 1). The water content was related to the intensity of juiciness as the groups (II and III) with a higher content of water were juicier (Table 1, Figure 4). Juiciness of meat is associated with the moisture that a consumer perceives in the first phase of chewing. According to Fortin et al. [2005], the most important attributes for the consumer during meat consumption are juiciness, tenderness, flavor, and the absence of off-flavors. Tougan et al. [2013] mentioned that a higher content of intramuscular fat, comprising more unsaturated fatty acids, promotes the perception of juiciness of meat. In the presented study, the goose meat product from the group I was characterized as containing less water, more fat and more protein and simultaneously was considered less juicy and more tender. Probably, the effect of fat on tenderness, but not on juiciness can be observed in this group. In this case, the stronger effect could be related to the water content. It should also be noted that in groups II and III, the higher water content may have resulted from a higher salt content, which increases the water absorption of meat. $\mathrm{NaCl}$ may improve tenderness in different ways, such as the solubilization of proteins from myofilaments [Martuscelli et al., 2015]. Fat content was positively correlated with the intensity of smoked odor and flavor. It is known that fat, as a source of flavor, can increase the intensity of taste sensations (in this case - the dominant taste of smoked meat) and generally flavor is the most important factor in consumers' food choices. The complex studies concerning the importance of sensory attributes and their perception by consumers have shown that independently of a kind of a product, flavor

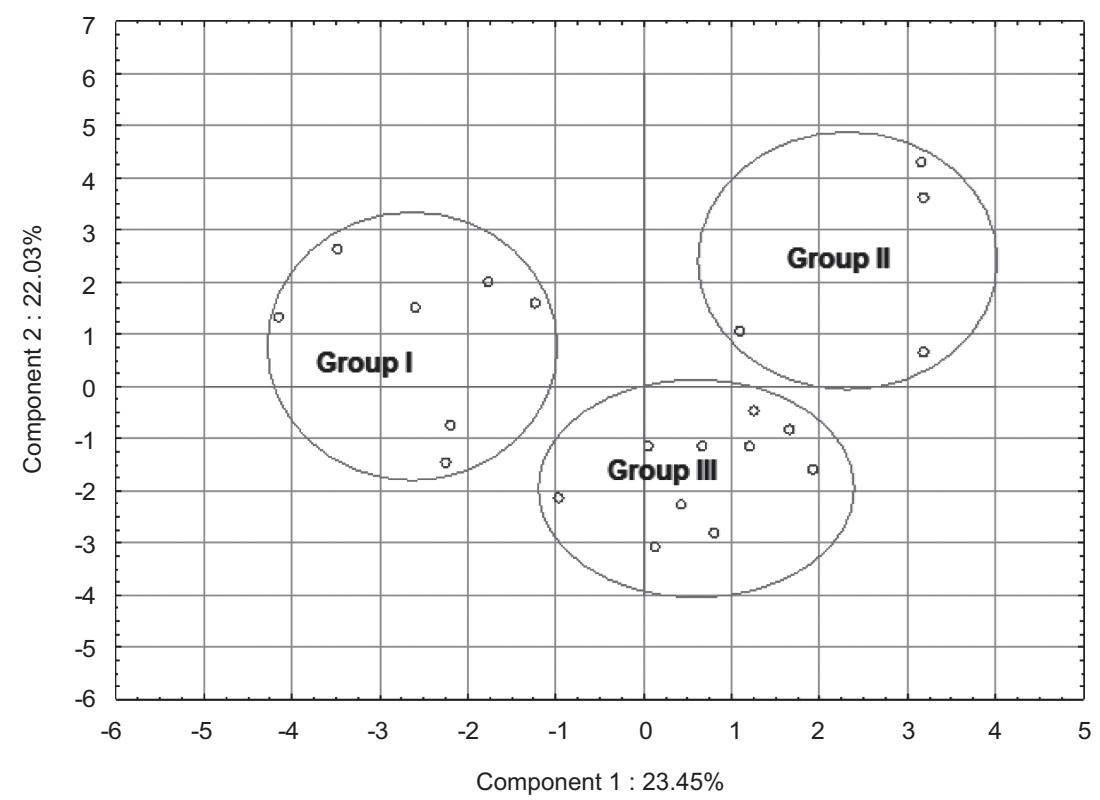

FIGURE 3. Results of the Principal Component Analysis (PCA) - spatial distribution of all analyzed samples for two principal components. 


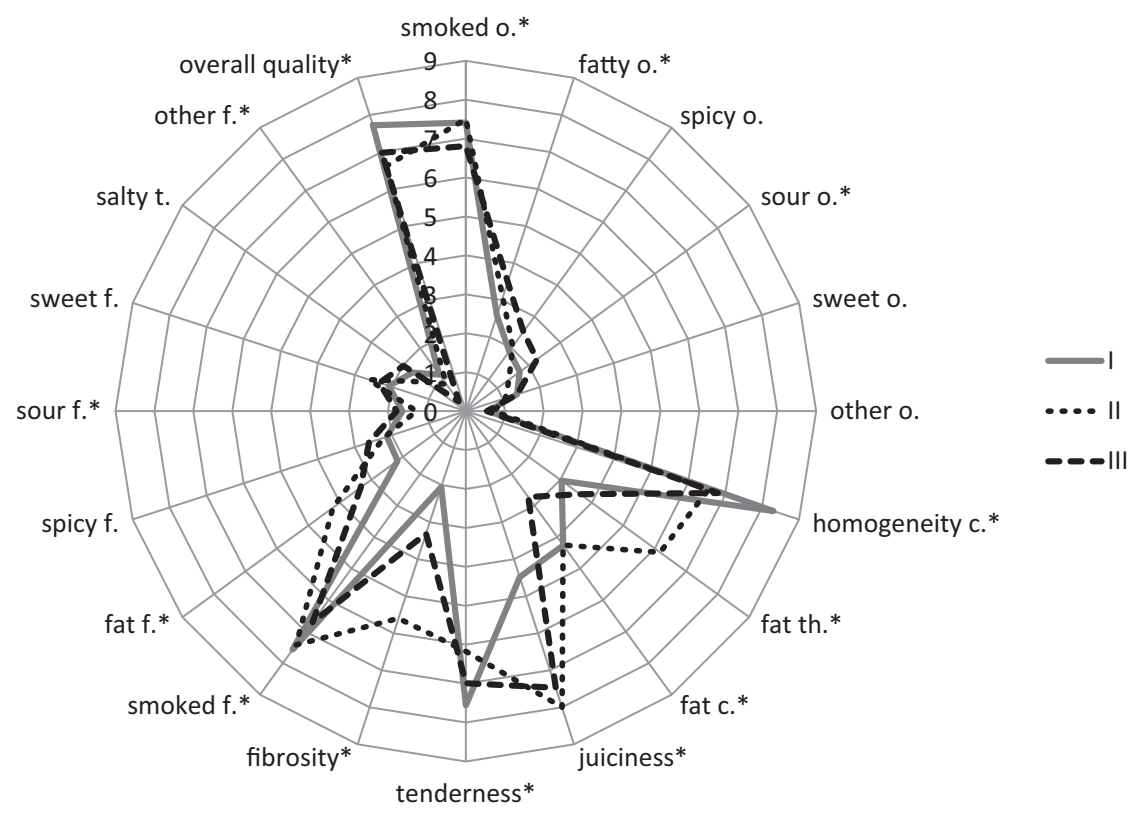

FIGURE 4. Characteristics of the sensory quality of three gropus differring in their sensory profile c - color, o - odor, th - thickness, $\mathrm{f}-\mathrm{flavor}$, $\mathrm{t}$ - taste (I, II and III are groups from Fig. 3).

is always the most important attribute of food products, followed by texture and appearance [Szcześniak, 2002; Jaworska \& Hoffmann, 2008].

Fat is the source of flavor in meat and is particularly important for the characteristics of specific flavor variations [Anandh \& Lakshmanan, 2014]. Fat is one of the precursors of flavor by combining with amino acids from proteins and other components when heated. In this study, the cover fat could absorb the compounds from the smoke. It has been proven that when fat melts it releases flavors [Dinh et al., 2006].

Nevertheless, it can be observed in the study that fibrosity is associated with the connective tissue content. Group II with the highest fibrosity had the highest content of connective tissue, although this difference was not statistically significant.

\section{Volatile compounds profile of pótgęsek}

The characteristics of all the studied groups in relation to volatile compounds identified in the headspace of the traditional product made from cured and smoked goose meat are presented in Table 2. A total of 46 chemical compounds were detected in the studied extract. The determined fragrance volatile compounds were grouped according to their probable origin using literature works as shown in Table 2. They were assigned to the following chemical classes: acids, alcohols, aldehydes, aliphatic hydrocarbons, alkanes, aromatic hydrocarbons, phenolic compounds, cyclic ketones, cyclopentanones, esters, furans, hydrocarbons, ketones, lactones, phenolic compounds, phenols, polycyclic aromatic hydrocarbons, pyridines, terpenes and glycols [Hierro et al., 2004]. The selected groups differed significantly and the sensory profile specific for each group was reflected in the profile of volatile compounds. Many significant differences were additionally obtained in this case. They are related to the volatile compounds from lipid oxidation (hexanal + octane, 1-heptanol, 2-heptanone, dodecane), volatile compounds from smoke
TABLE 1. Characteristics of physicochemical parameters of selected groups, varying as regards the sensory quality of pótgęsek.

\begin{tabular}{lcccc}
\hline Traits & I & II & III \\
\hline Water (\%) & $58.62 \pm 4.09^{\mathrm{a}}$ & $67.32 \pm 3.61^{\mathrm{b}}$ & $71.06 \pm 2.73^{\mathrm{b}}$ \\
Fat (\%) & $15.99 \pm 4.74^{\mathrm{a}}$ & $13.71 \pm 3.88^{\mathrm{a}}$ & $8.96 \pm 3.03^{\mathrm{b}}$ \\
Protein (\%) & $22.99 \pm 2.23^{\mathrm{a}}$ & $14.04 \pm 1.34^{\mathrm{b}}$ & $15.95 \pm 1.18^{\mathrm{b}}$ \\
Connective tissue (\%) & $1.87 \pm 0.52$ & $2.16 \pm 0.24$ & $1.62 \pm 0.47$ \\
$\mathrm{NaCl}(\%)$ & $1.85 \pm 0.34^{\mathrm{a}}$ & $2.89 \pm 0.47^{\mathrm{b}}$ & $2.40 \pm 0.41^{\mathrm{b}}$ \\
$\mathrm{pH}$ & $5.94 \pm 0.14$ & $6.00 \pm 0.12$ & $6.11 \pm 0.23$
\end{tabular}

Color parameters:

$\begin{array}{cccc}L^{*} & 48.58 \pm 4.49^{\mathrm{ab}} & 44.51 \pm 2.82^{\mathrm{a}} & 48.90 \pm 1.76^{\mathrm{b}} \\ \mathrm{a}^{*} & 18.49 \pm 1.79 & 19.62 \pm 2.19 & 20.11 \pm 1.25 \\ \mathrm{~b}^{*} & 8.73 \pm 0.84^{\mathrm{a}} & 7.39 \pm 0.41^{\mathrm{b}} & 8.12 \pm 0.48^{\mathrm{ab}}\end{array}$

a,b Means in the same row with different letters are significantly different $(\mathrm{P} \alpha \leq 0.05)$. I, II and III are groups from Figure 3.

(3 + 4-methyl-phenol, o-guaiacol, 2-methoxy-4-methyl-phenol, syringol, phenol), volatile compounds from amino acid degradation (3-methyl-butanal, benzaldehyde), volatile compounds from spices (alpha-pinene, eugenol, carvacrol, 4-vinyl guaiacol, caryophyllene), and others (2,2,4,6,6-pentamethylheptane, 2-methanethiol, cyclohexanone, 2-methyl-pyridine, naphthalene, 3-methyl-2(5h)-furanone) (Table 2).

Products of degradation and then oxidation of fatty acids were the most significant group of volatile compounds identified in pótgęsek samples (59\%). Such a result is probably connected with the high content of polyunsaturated fatty acids (PUFA) in goose meat, which are the substratum of autoxidation [Hierro et al., 2004]. Considering the class of volatile compounds, hydrocarbons were most abundant (hexane, 
TABLE 2. Characteristics of selected groups by the identified volatile compounds (\% of the total area).

\begin{tabular}{|c|c|c|c|c|c|c|}
\hline \multirow{2}{*}{ Family } & \multirow{2}{*}{$\begin{array}{c}\text { Linear } \\
\text { Retention Index } \\
\text { (LRI) }\end{array}$} & \multicolumn{3}{|c|}{ Group } & \multirow{2}{*}{ Family } & \multirow{2}{*}{$\begin{array}{l}\text { Source of volatile } \\
\text { compounds }\end{array}$} \\
\hline & & I & II & III & & \\
\hline Hexane & 600 & $29.44 \pm 4.56$ & $25.09 \pm 3.94$ & $29.04 \pm 3.09$ & alkanes & \multirow{11}{*}{$\begin{array}{c}\text { lipid oxidation } \\
\text { [Bruna et al., 2001; } \\
\text { Hierro et al., 2004; } \\
\text { Muriel et al., 2004; } \\
\text { Pastorelli et al., 2003; } \\
\text { Sánchez-Peña } \\
\text { et al., 2005] }\end{array}$} \\
\hline Heptane & 700 & $22.71 \pm 4.72$ & $23.25 \pm 3.30$ & $23.13 \pm 3.93$ & alkanes & \\
\hline Hexanal + octane & 800 & $5.97 \pm 4.42^{\mathrm{a}}$ & $1.67 \pm 0.49^{b}$ & $2.01 \pm 0.95^{b}$ & aldehydes & \\
\hline Octanal & 1004 & $0.61 \pm 0.29$ & $0.41 \pm 0.10$ & $0.62 \pm 0.63$ & aldehydes & \\
\hline Heptanal & 903 & $0.62 \pm 0.24$ & $0.30 \pm 0.07$ & $0.35 \pm 0.27$ & aldehydes & \\
\hline Nonanal & 1106 & $1.64 \pm 0.92$ & $1.35 \pm 0.34$ & $2.05 \pm 1.10$ & aldehydes & \\
\hline Decanal & 1208 & $0.09 \pm 0.05$ & $0.04 \pm 0.03$ & $0.13 \pm 0.15$ & aldehydes & \\
\hline 1-Hexanol & 871 & $0.36 \pm 0.14$ & $0.23 \pm 0.08$ & $0.22 \pm 0.11$ & alcohols & \\
\hline 1-Heptanol (unpure) & 976 & $0.18 \pm 0.05$ & NA & NA & alcohols & \\
\hline 2-Heptanone & 893 & $0.18 \pm 0.05^{\mathrm{a}}$ & $0.04 \pm 0.01^{b}$ & $0.05 \pm 0.04^{b}$ & ketones & \\
\hline Dodecane (unpure) & 1200 & $0.14 \pm 0.05^{\mathrm{a}}$ & $\mathbf{N A}$ & $\mathbf{0 . 0 3} \pm 0.04^{b}$ & $\begin{array}{c}\text { aliphatic } \\
\text { hydrocarbons }\end{array}$ & \\
\hline 3+4-Methyl-phenol & 1080 & $1.07 \pm 0.38^{a}$ & $1.06 \pm 0.50^{\mathrm{a}}$ & $0.59 \pm 0.38^{b}$ & phenols & \multirow{11}{*}{$\begin{array}{l}\text { smoke } \\
\text { [Hierro et al., 2004; } \\
\text { Naeher et al., 2007; } \\
\text { Théron et al., 2010; } \\
\text { Yu et al., 2008] }\end{array}$} \\
\hline o-Guaiacol & 1090 & $1.68 \pm 0.55^{a}$ & $4.74 \pm 1.80^{b}$ & $3.32 \pm 1.28^{b}$ & phenols & \\
\hline 2-Methoxy-4-methyl-phenol & 1193 & $0.64 \pm 0.18^{a}$ & $2.14 \pm 0.88^{b}$ & $1.64 \pm 0.69^{b}$ & phenols & \\
\hline Syringol & 1353 & $\mathbf{0 . 1 8} \pm 0.05^{\mathrm{a}}$ & $0.55 \pm 0.18^{b}$ & $0.46 \pm 0.26^{b}$ & phenols & \\
\hline o-Cresol / gamma-terpinen & 1060 & $0.47 \pm 0.16$ & $0.68 \pm 0.22$ & $0.92 \pm 1.24$ & $\begin{array}{l}\text { phenols } \\
\text { (derivative) }\end{array}$ & \\
\hline Toluene & 756 & $5.06 \pm 3.18$ & $5.71 \pm 0.70$ & $5.14 \pm 2.73$ & $\begin{array}{c}\text { aromatic } \\
\text { hydrocarbons }\end{array}$ & \\
\hline Furfural & 828 & $1.27 \pm 1.20$ & $2.07 \pm 1.35$ & $1.43 \pm 0.82$ & aldehydes & \\
\hline 2-Furanmethanol & 859 & $1.85 \pm 0.73$ & $2.55 \pm 0.91$ & $1.66 \pm 0.55$ & alcohols & \\
\hline 2-Methyl-2-cyclopenten-1-one & 905 & $0.58 \pm 0.30$ & $0.84 \pm 0.15$ & $0.66 \pm 0.28$ & alkene & \\
\hline Phenol & 988 & $2.14 \pm 0.57^{a}$ & $1.13 \pm 0.41^{b}$ & $0.71 \pm 0.46^{b}$ & carbolic acid & \\
\hline 2-Cyclopenten-1-one, 2,3-dimethyl & 1039 & $0.16 \pm 0.18$ & $0.18 \pm 0.61$ & $0.12 \pm 0.31$ & cycloalkene & \\
\hline Acetic acid & 629 & $2.21 \pm 0.95$ & $3.37 \pm 0.96$ & $3.49 \pm 1.22$ & acid & $\begin{array}{l}\text { carbohydrate } \\
\text { fermentation }\end{array}$ \\
\hline Ethanol & - & $0.62 \pm 0.51$ & $0.62 \pm 0.74$ & $0.86 \pm 1.13$ & alcohols & [Soncin et al., 2007] \\
\hline 3-Methyl-butanal & 645 & $0.34 \pm 0.20^{\mathrm{a}}$ & $0.54 \pm 0.37^{b}$ & $0.22 \pm 0.09^{a}$ & aldehydes & \multirow{3}{*}{$\begin{array}{c}\text { amino acid degradation } \\
\text { [Masson } \text { et al., } \\
\text { 2015;Olivares } \\
\text { et al., 2009; } \\
\text { Resconi et al., 2013] } \\
\text { micr. esterific. } \\
\text { [Lorenzo et al., 2013; } \\
\text { Yu et al., 2008] }\end{array}$} \\
\hline Benzaldehyde & 960 & $0.67 \pm 0.20^{a}$ & $0.35 \pm 0.10^{b}$ & $0.38 \pm 0.09^{b}$ & aldehydes & \\
\hline Butanoic acid, methyl ester & 717 & $0.31 \pm 0.12$ & $0.31 \pm 0.22$ & $0.42 \pm 0.19$ & esters & \\
\hline Alpha pinene & 933 & $0.08 \pm 0.06^{\mathrm{a}}$ & $0.31 \pm 0.31^{b}$ & $0.57 \pm 0.31^{b}$ & terpenes & \multirow{7}{*}{ [Lorenzo et al., 2012] } \\
\hline Cymene & 1024 & $0.02 \pm 0.02$ & $0.12 \pm 0.12$ & $1.97 \pm 1.97$ & terpenes & \\
\hline Limonene / corylon & 1028 & $0.52 \pm 0.21$ & $1.59 \pm 1.18$ & $0.98 \pm 0.68$ & terpenes & \\
\hline Eugenol & 1360 & nd & $0.20 \pm 0.19$ & $0.19 \pm 0.10$ & terpenes & \\
\hline Carvacrol & 1303 & nd & $0.01 \pm 0,02$ & $0.11 \pm 0,10$ & $\begin{array}{l}\text { phenols } \\
\text { (derivative) }\end{array}$ & \\
\hline 4-Vinylguaiacol & 1315 & $0.04 \pm 0.03^{\mathrm{a}}$ & $0.14 \pm 0.05^{b}$ & $0.12 \pm 0.10^{b}$ & phenols & \\
\hline Caryophyllene & 1423 & nd & $0.06 \pm 0.10$ & $0.08 \pm 0.06$ & sesquiterpens & \\
\hline
\end{tabular}




\begin{tabular}{|c|c|c|c|c|c|c|}
\hline \multirow{2}{*}{ Family } & \multirow{2}{*}{$\begin{array}{c}\text { Linear } \\
\text { Retention Index } \\
\text { (LRI) }\end{array}$} & \multicolumn{3}{|c|}{ Group } & \multirow{2}{*}{ Family } & \multirow{2}{*}{$\begin{array}{l}\text { Source of volatile } \\
\text { compounds }\end{array}$} \\
\hline & & I & II & III & & \\
\hline 2,2,4-Trimethyl-pentane & 682 & $13.18 \pm 4.11$ & $13.12 \pm 3.13$ & $12.95 \pm 2.38$ & alkanes & \\
\hline 2,2,4,6,6-Pentamethyl-heptane & 990 & $1.52 \pm 0.86^{\mathrm{a}}$ & $0.60 \pm 0.46^{b}$ & $\mathbf{0 . 5 4} \pm 0.48^{b}$ & alkanes & \\
\hline Methanethiol & - & $0.12 \pm 0.14$ & nd & $0.03 \pm 0.06$ & acid & \\
\hline 2-Furnacarboxaldehyde, 5-methyl & 966 & $0.82 \pm 0.46$ & $1.35 \pm 0.62$ & $0.89 \pm 0.45$ & aldehydes & \\
\hline Cyclohexanone & 890 & $0.13 \pm 0.09^{a}$ & $0.02 \pm 0.03^{b}$ & $0.002 \pm 0.01^{\mathrm{b}}$ & cyclic ketones & \\
\hline 2,3-Butanediol & 798 & $0.22 \pm 0.12$ & $0.09 \pm 0.06$ & $012 \pm 0.09$ & glycol & \\
\hline 2-Methyl-pyridine & 816 & $0.14 \pm 0.13^{a}$ & $0.03 \pm 0.03^{b}$ & nd & hydrocarbons & $\begin{array}{l}\text { [Lorenzo et al., 2012; } \\
\text { Lorenzo et al., 2013] }\end{array}$ \\
\hline Naphthalene & 1180 & $0.25 \pm 0.12$ & nd & nd & $\begin{array}{c}\text { polycyclic } \\
\text { aromatic } \\
\text { hydrocarbons }\end{array}$ & \\
\hline 1-(2-Furanyl)-ethanone & 912 & $0.19 \pm 0.12$ & $0.29 \pm 0.14$ & $0.22 \pm 0.11$ & ketones & \\
\hline Butyrolactone & 915 & $0.58 \pm 0.30$ & $0.37 \pm 0.08$ & $0.35 \pm 0.14$ & lactones & \\
\hline $\begin{array}{l}\text { 2(5H)-Furanone, } \\
\text { 3-methyl-(unpure) }\end{array}$ & 981 & $0.14 \pm 0.05^{a}$ & $0.41 \pm 0.16^{b}$ & $0.23 \pm 0.09^{a}$ & lactones & \\
\hline 4-Ethylguaiacol & 1281 & $0.27 \pm 0.10$ & $0.50 \pm 0.26$ & $0.41 \pm 0.23$ & phenols & \\
\hline
\end{tabular}

a,b Means in the same row with different letters are significantly different ( $\mathrm{P} \alpha \leq 0.05)$ (I, II and III are groups from Figure 3).

heptane). It is necessary to emphasize that because of the relatively high odor, threshold values probably had no significant contribution in final aroma development in the analyzed product. Straight-chain aliphatic aldehydes are the typical products of lipid oxidation with very low odor thresholds [Muriel et al., 2004]. Saturated aliphatic aldehydes from C6 up to $\mathrm{C} 10$ were detected in the pótgęsek samples. The most abundant representative of this group of compounds was hexanal, which probably derives from the oxidation of unsaturated fatty acids such as linoleic and arachidonic acid [Sánchez-Peña et al., 2005]. It has low odor threshold, namely 5.87 ppm, and it is responsible for rancid flavor [Biesiada-Drzazga, 1995]. Moreover, high levels of hexanal were detected in other cold meats, for example dry fermented sausages [Bruna et al., 2001]. The aroma of hexanal is perceived as unpleasant, rancid, nauseating, hot, similar to aroma of green leaves, vegetables, or grass [Górska et al., 2016]. It can be deduced that this compound had an impact on the aroma of the studied pótgęsek. Saturated aldehydes (heptanal, octanal, nonanal, decanal) can also originate from the autoxidation of unsaturated fatty acids, like e.g. from arachidonic, linolenic, linoleic, or oleic acid [Pastorelli et al., 2003]. They impart characteristic odors, i.e. potato aroma, oily fatty (heptanal), oily, fatty, soapy, geranium, herbal, floral (octanal), soapy-fruity, tallow, plastic, soapy (nonanal) or potato-butter (decanal) [Marco et al., 2007]. Due to their low odor threshold values, aldehydes play a significant role in the development of meat products aroma. They impart products specific odors, such as butter, toasted sweet, floral or green odors [Olivares et al., 2009]. Another group of volatile compounds identified in pótgęsek were alcohols (1-hexanol and 1-heptanol), which probably originated from the reduction of corresponding aldehydes derived from lipid oxidation. The alcohols, the aliphatic ones in particular, also play a significant role in the development of product aroma. 1-Hexanol is responsible for toasty, green, dry aroma, and 1-heptanol for green aroma [Insausti et al., 2002]. Another group of volatile compounds originating from lipolytic transformations includes ketones. The only identified representative of this group was 2-heptanon. Ketones, especially 2-ketones, are considered to be compounds having a crucial impact on the development of aroma of not only meat and meat products. It needs to be emphasized that in the tested products significant differences were obtained only in the content of hexanal + octane, 2-heptanone, and dodecane. There is no clear link to any specific odor. It seems that the higher content of these compounds in group I could be responsible for the formation of another flavor (Table 2).

Another quite numerous group of volatile compounds identified in the pótgessek samples were the substances originating from meat smoking. These were the compounds belonging to HA (aromatic hydrocarbons) - all of which are compounds specific for wood smoke [Hierro et al., 2004]. Phenols are compounds which inhibit oxidative degradation of lipids, and also to impair the growth of microorganisms, thus significantly improving the storage stability of smoked products [Yu et al., 2008]. Additionally, methylbenzene (toluene), representing the family of aromatic hydrocarbons, is most probably the product of cyclization of unsaturated carboxylic chains during lipid degradation or from environmental contamination [Théron et al., 2010]. In this case, significant differences were observed for four volatile compounds. Group I differed significantly from II and III with lower contents of three phenols (o-guaiacol, 2-metoxy4-methyl-phenol, syringol) and with higher contents of phenolic compounds from both groups. There were significant differences in the case of phenol, which were partly related to 
higher smoked odor and flavor in group I and a higher level of phenols in group II (Table 2).

The results of sensory evaluation confirmed the significant role of volatile compounds in creating the flavor and aroma of pótgęsek. Among the analyzed features of aroma, the intensity of smoked meat aroma was rated best as for cold meats from all producers. The results of a correlation analysis conducted between the determined contents of volatile compounds and sensory attributes showed that only 2-methyl-pyridine indicated a statistically significant role in creating the smoked meat aroma. It is the compound of a pyridine group, which is a typical compound of wood smoke. The results of sensory analysis also showed that the attribute of smoked meat flavor gained the highest intensity in all the analyzed samples (average: 7.6 - producer I, 6.8 - producer II, 7.0 - producer III). In this case, four volatile compounds were statistically significant correlated with the intensity of smoked meat flavor. These were 2-methyl-pyridine, 2-furanmethanol, phenol, 2,3-dimethyl-2-cyclopenten-1-one, and 3+4-methyl-phenol, which are typical wood smoke compounds [Naeher et al., 2007].

Ethanol and acetic acid identified in pótgessek samples are most probably the products of saccharide fermentation. The presence of these volatile compounds confirmed the metabolic activity of microorganisms occurring in cold meats. Acetic acid gives products pungent, vinegar odor. It is worth mentioning that the presence of acetic acid was also confirmed in raw goose meat [Soncin et al., 2007]. However, no significant differences were observed between the analyzed groups.

Leucine and isoleucine are precursors of 3-methylbutanal and similarly phenylalanine is a precursor of benzeneacetaldehyde. These conversions are mediated by microbial action, and have been thoroughly studied [Masson et al., 1999]. The content of benzeneacetaldehyde increases significantly during ripening and fermentation. Both identified volatile compounds originating from amino acid degradation have a significant influence on the aroma of products in which they occur - in this case, on the odor of pótgęsek. Moreover, 3 -methylbutanal is often formed as a result of the Strecker degradation of amino acids - valine, isoleucine and leucine, or is a product of microbial metabolism [Resconi et al., 2013]. In the studies by other authors, 3-methylbutanal was also found in high proportions in beef meats [Resconi et al., 2013]. Moreover, Olivares et al. [2009] have demonstrated that 3-methylbutanal is produced in the initial phase of cold meats maturation. A higher content of 3-methylbutanal was noted in group II and benzaldehyde in group I (Table 2).

Butanoic acid, a methyl ester present in the pótgęsek samples, is a volatile compound originating from microbial esterification. It is responsible for a persistent, rancid, butter-like odor and a burning acid flavor. Based on other studies, it may be stated that this compound occurred also in other cold meats, such as semi-ripened sausage or dry-cured loin [Lorenzo et al., 2013]. This research demonstrates that the content of butanoic acid, methyl ester, and also hexanoic, heptanoic, pentanoic and decanoic acids, was decreasing in the course of food storage [Yu et al., 2008]. Terpenes, phenols and their derivatives present in pótgessek samples were aroma com- pounds originating from spices. The presence of terpenes may also result from animal feedstuffs, but they mainly come from the spices used in dry-cured sausage production [Lorenzo et al., 2012]. Limonene and cymene belonging to the group of terpenes were identified in the greatest quantity. Limonene is a component of many essential oils of spices and is particularly abundant in nutmeg and black pepper. The typical aromas of terpenes are well established. For example, alphapinene has a characteristic pine odor, and limonene gives a bit of lemon aroma. Nevertheless, according to the results presented in Table 2, group I was characterized by lower contents of alpha-pinene and 4-vinyl guaiacol which corresponded to lower spicy odor and flavor (Figure 4, Table 2) (although these differences were not significant).

It is worth noting that carvacrol content was negatively correlated with the intensity of smoked meat odor. It indicates the probability of masking or eliminating the intensity of smoked meat aroma by spices addition. Furthermore, contents of essential oils originating from spices were negatively correlated with the attribute of smoked meat flavor. It was not only carvacrol, but also $\alpha$-pinene, an aroma compound originating probably from the addition of cumin, cymene, or from rosemary. The addition of spices could mask the perception of smoked meat flavor.

The characteristics of the determined volatile compounds shows also significant differences in the content of these odorants among previously separated groups (Table 2). The statistical analysis proves that the aromas of groups II and III were quite similar. Group II stood out only in terms of the highest content of 3-methylbutanal. Group III was characterized by the lowest content of $3+4$-methylphenol. Group I was the most diverse in terms of the content of volatile compounds. It was characterized by the highest concentration of 2-heptanone and dodecane, compounds probably derived from lipid oxidation. This fact is also confirmed by the highest fat content determined in meat products from this group. Moreover, group I was characterized by the lowest content of alphapinene and 4-vinyl guaiacol, odorants that are components of the essential oils of spices. It can therefore be assumed that the addition of spices in this group was the lowest, which was confirmed by the results of sensory analysis, where spicy odor was the least perceptible. Noteworthy is also that products from group I had the lowest syringol and phenol contents, but a high content of benzaldehyde. These compounds created the specific composition of the aroma of smoked meat.

It should be noted that the olfactory bouquet of pótgęsek also included volatile compounds with unrecognized aroma and difficult to determine origin, i.e. heptane, cyclohexanone, 2-methyl pyridine, and naphthalene. These compounds were most common in products from group I, where perhaps they could also correspond with the most intense other odor sensations.

\section{CONCLUSIONS}

Meat products of each producer were characterized by a specific profile of volatile compounds and chemical composition, which was reflected in the unique and specific sensory profile of flavor, aroma and texture. 
Relatively high variation in the quality of the traditional product made from goose meat was noticed.

High volatility was probably due to the impact of production technologies used by different producers, which is reflected in the diversified chemical composition and sensory quality of the analyzed meat products.

\section{RESEARCH FUNDING}

This study was financed by the statutory activity Grant No. 505-10-100500-L00333-99.

\section{CONFLICT OF INTEREST}

Authors declare no conflict of interest.

\section{REFERENCES}

1. Anandh M.A., Lakshmanan V., Storage stability of smoked buffalo rumen meat product treated with ginger extract. J. Food Sci. Technol., 2014, 51, 1191-1196.

2. Biesiada-Drzazga B., Detectable odor thresholds of selected lipid oxidation compounds in a meat model system. J. Food Sci., 1995, 60, 592-595.

3. Bruna J.M., Hierro E.M., de la Hoz L., Mottram D.S., Fernandez M., Ordonez J.A., The contribution of Penicillium aurantiogriseum to the volatile composition and sensory quality of dry fermented sausages. Meat Sci., 2001, 59, 97-107.

4. Cayot N., Sensory quality of traditional foods. Food Chem., 2007, 101, 1, 154-162.

5. Dinh T., Nhat T., Meat quality: understanding of meat tenderness and influence of fat content on meat flavor. J. Food Sci. Technol., 2006, 9, 12, 65-70.

6. Fortin A., Robertson W.M., Tong A.K.W., The eating quality of Canadian pork and its relationship with intramuscular fat. Meat Sci., 2005, 69, 297-305.

7. Górska E., Przybylski W., Nowicka K., Jaworska D., Tambor K., Relationship between sensory attributes and volatile compounds of Polish dry-cured loin. Asian Australas. J. Anim. Sci., 2016, doi: http://dx.doi.org/10.5713/ajas.16.0252.

8. Guerrero L., Claret A., Verbeke W., Enderli G., Żakowska-Biemans S., Vanhonacker F., Issanchou S., Sajdakowska M., Signe Granli B., Scalvedi L., Contel M., Hersleth M., Perception of traditional food products in six European countries using free word association. Food Qual. Prefer., 2010, 21, 2, 225-233.

9. Hierro E., de la Hoz L., Ordonez J.A., Headspace volatile compounds from salted and occasionally smoked dried meats (cecinas) as affected by animal species. Food Chem., 2004, 45, 649-657.

10. Insausti K., Beriain M. J., Gorraiz C., Purroy A., Volatile compounds of raw beef from 5 local Spanish cattle breeds stored under modified atmosphere. J. Food. Sci., 2002, 67, 1580-1589.

11. ISO 13299:2016. Sensory analysis. Methodology. General Guidance for establishing a sensory profile.

12. ISO 8586-2:1996. Sensory analysis. General guidance for the selection, training and monitoring of assessors part II - Experts.

13. Jaworska D., Hoffmann M., Relative importance of texture properties in the sensory quality and acceptance of crispy products. J. Sci. Food Agric., 2008, 88, 1804-1812.
14. Kluk K., Domestic and wild animals, particularly domestic, natural history and origins of the farm. Necessary and useful household behavior, reproduction, disease treatment, wild catching, taming, ingestion of harmful and extermination. 1813, Scholarum Piarum, Warsaw, pp. 321-322 (in Polish).

15. Lorenzo J.M., Bedia M., Bañón S., Relationship between flavour deterioration and the volatile compound profile of semi-ripened sausage. Meat Sci., 2013, 93, 614-620.

16. Lorenzo J.M., Montes R., Purriños L., Franco D., Effect of pork addition on the volatile compounds of foal dry-cured sausage. Meat Sci., 2012, 91, 506-512.

17. Marco A., Navarro J.L., Flores M., Quantification of selected odor-active constituents in dry fermented sausages prepared with different curing salts. J. Agric. Food Chem., 2007, 55, 3058-3065.

18. Martuscelli M., Lupieri L., Chaves-Lopez C., Mastrocola D., Pittia P., Technological approach to reduce $\mathrm{NaCl}$ content of traditional smoked dry-cured hams: effect on quality properties and stability. J. Food Sci. Techol., 2015, 08, 1-12.

19. Marušić N., Petrović M., Vidaček S., Petrak T., Medić H., Characterization of traditional Istrian dry-cured ham by means of physical and chemical analyses and volatile compounds. Meat Sci., 2011, 88, 786-790.

20. Masson F., Hinrichsen L., Talon R., Montel M.C., Factors influencing leucine catabolism by a strain of Staphylococcus carnosus. Int. J. Food. Microbiol., 1999, 49, 173-178.

21. Muriel E., Antequera T., Petron M. J., Andres A. I., Ruiz J., Volatile compounds in Iberian dry-cured loin. Meat. Sci., 2004, 68, 391-400.

22. Naeher L.P., Brauer M., Lipsett M., Zelikoff J. T., Simpson C.D., Koenig J., Smith K.R., Woodsmoke health effects: a review. Inhal. Toxicol., 2007, 19, 67-106.

23. Olivares A., Navarro J. L., Flores M., Establishment of the contribution of volatile compounds to the aroma of fermented sausages at different stages of processing and storage. Food Chem., 2009, 115, 1464-1472.

24. Pastorelli G., Magni S., Rossi R., Pagliarini E., Baldini P., Dirinck P., Influence of dietary fat, on fatty acid composition and sensory properties of dry cured Parma ham. Meat Sci., 2003, 65, $571-580$.

25. Resconi V.C., Escudero A., Campo M.M., The development of aromas in ruminant meat. Molecules, 2013, 18, 6748-6781.

26. Sánchez-Peña C.M., G. Luna D.L. García-González Aparicio R., Characterization of French and Spanish dry-cured hams: influence of the volatiles from the muscles and the subcutaneous fat quantified by SPME-GC. Meat Sci., 2005, 69, 635-645.

27. Soncin S., Chiesa L.M., Cantoni C., Biondi P.A., Preliminary study of the volatile fraction in the raw meat of pork, duck and goose. J. Food Compos. Anal., 2007, 20, 436-439.

28. Stahnke L.H., Aroma components from dry sausages fermented with Staphylococcus xylosus. Meat Sci., 1994, 38, 39-53.

29. StatSoft, Inc. (2014). STATISTICA (data analysis software system), version 12. [www.statsoft.com].

30. Szcześniak A.S., Texture is a sensory property. Food Qual. Prefer., 2002, 13, 215-225.

31. Théron L., Tournayre P., Kondjoyan N., Abouelkaram S., Santé-Lhoutellier V., Berdagué J.L., Analysis of the volatile profile and identification of odour-active compounds in Bayonne ham. Meat Sci., 2010, 85, 453-460. 
32. Tougan P.U., Dahouda M., Salifou C.F., Ahounou S.G., Kpodekon M.T., Mensah G.A., Thewis A., Karim I.Y., Conversion of chicken muscle to meat and factors affecting chicken meat quality: a review. Int. J. Adv. Agric. Res., 2013, 3, 8, 1-20 [http://www.innspub.net/wp-content/uploads/2013/08/IJAARV3No8-p1-20.pdf].

33. Yu A.N., Sun B.G., Tian B.T., Qu W.Y., Analysis of volatile compounds in traditional smoke-cured bacon (CSCB) with different fiber coatings using SPME. Food Chem., 2008, 110, 233-238.
34. Żakowska-Biemans S., Sajdakowska M., Issanchou S., Impact of innovation on consumers liking and willingness to pay for traditional sausages. Pol. J. Food Nutr. Sci., 2016, 66, 119-127.

Submitted: 19 January 2016. Revised: 28 July and 10 September 2016. Accepted: 23 September 2016. Published on-line: 19 January 2017. 